Abstracta Iranica Abstanica

Revue bibliographique pour le domaine irano-aryen

Volume 32-33 | 2013

Comptes rendus des publications de 2009-2010

\title{
Kristen Blake. The U.S.-Soviet Confrontation in Iran, 1945-1962. A Case in the Annals of the Cold War
}

\section{Clément Therme}

\section{(2) OpenEdition}

1 Journals

\section{Édition électronique}

URL : http://journals.openedition.org/abstractairanica/41007

DOI : 10.4000/abstractairanica.41007

ISSN : 1961-960X

Éditeur :

CNRS (UMR 7528 Mondes iraniens et indiens), Éditions de l'IFRI

\section{Édition imprimée}

Date de publication : 1 décembre 2013

ISSN : 0240-8910

Référence électronique

Clément Therme, «Kristen Blake. The U.S.-Soviet Confrontation in Iran, 1945-1962. A Case in the Annals of the Cold War », Abstracta Iranica [En ligne], Volume 32-33 | 2013, document 446, mis en ligne le 01 juillet 2016, consulté le 26 septembre 2020. URL : http://journals.openedition.org/ abstractairanica/41007; DOI : https://doi.org/10.4000/abstractairanica.41007

Ce document a été généré automatiquement le 26 septembre 2020.

Tous droits réservés 


\title{
Kristen Blake. The U.S.-Soviet Confrontation in Iran, 1945-1962. A Case in the Annals of the Cold War
}

\author{
Clément Therme
}

\section{RÉFÉRENCE}

Kristen Blake. The U.S.-Soviet Confrontation in Iran, 1945-1962. A Case in the Annals of the Cold War. Lanham, University Press of America, 2009, 224 p.

1 Cet ouvrage est le fruit d'une recherche universitaire de premier plan : il s'agit en effet d'une version révisée et actualisée d'une thèse soutenue à l'université de Harvard en 1999. Parmi ses qualités principales, on notera la qualité des sources américaines, britanniques, russes et iraniennes. L'A. a utilisé une documentation variée et d'une grande pertinence qui lui permet d'étayer son argumentation présentant l'Iran comme un cas d'étude dans les tensions entre l'Union soviétique et les Etats-Unis dans la période allant des origines de la guerre froide (1945-46) à la détente (1962). Une autre qualité de cette recherche est d'inscrire cette étude des relations triangulaires entre Moscou, Washington et Téhéran dans la longue durée incluant ainsi la politique britannique vis-à-vis de l'Iran au sein de la réflexion. Par ailleurs, l'apport de l'auteur à la littérature existante est clairement énoncé : il s'agit d'étudier le cas de l'Iran dans la rivalité américano-soviétique en établissant des liens entre les études qui ne concernent que la crise de 1945-46 et les origines de la guerre froide avec les ouvrages consacrés aux relations irano-américaines après la révolution islamique (1979). Si le projet de l'auteur paraitre de prime abord ambitieux, il est incontestable qu'il parvient à combler un vide existant concernant la période de la poursuite de la guerre froide américano-soviétique en Iran (1947-1962).

2 La richesse ainsi que le grand nombre de sources primaires et secondaires utilisées font de cet ouvrage le premier aussi complet et détaillé concernant une période essentielle 
de l'histoire des relations internationales de l'Iran contemporain. Il réussit enfin à dépasser le cas d'étude iranien pour proposer une approche critique de la grille de lecture des auteurs appartenant aux principales écoles de pensée des historiens de la Guerre Froide: les orthodoxes, les révisionnistes et les post-révionnistes. Cette recherche restera comme une référence en raison de son étendue et de sa dimension heuristique.

\section{AUTEURS}

\section{CLÉMENT THERME}

Paris 